\title{
An AR Model based Robust DOA Estimation
}

\author{
K.Radhakrishnan \\ M.A College of Engineering \\ Kothamangalam, Kerala, India-68666
}

\author{
A.Unnikrishnan \\ Naval Physical and Oceanographic Lab \\ Kochi,Kerala, India-682021
}

\begin{abstract}
This paper investigates the possibility estimating the direction of arrival (DOA) in a system identification perspective. The system is modeled as an autoregressive (AR) process and extended Kalman filter (EKF) is used to estimate the DOA, which forms a state of the augmented state vector of the EKF. The states generate the signals at a linearly phased array. Simulation results demonstrate the feasibility of the approach to estimate DOA to a reasonable degree of convergence especially at high SNRs.
\end{abstract}

\section{Categories and Subject Descriptors}

C.4 [Performance of systems]: C.4.3 - Measurement Techniques, C.4.4 - Modeling Techniques

C.3.4[Special Purpose and Application Base Systems(J.7)]:Signal Processing .

1.6.4 Simulation and Modeling (G.3) - Model

\section{General Terms}

AR Model, Estimation

\section{Keywords}

Modeling, Direction of arrival, Estimation

\section{INTRODUCTION}

The problem of estimating the direction of arrival of plane waves sampled by an array of sensors has extensively been investigated in the last decade[1]. Array signal processing has found important application in diverse areas such as radar, sonar, communication and seismic exploration. A problem central to the sensor array processing is the estimation of direction of arrival (DOA) of the signals [2]. Recently high resolution methods for this type have captured the attention of many researchers [2].

In this paper, the DOA estimation is viewed as a system identification problem. A recursive estimation system identification procedure based on extended Kalman algorithm is applied, which leads to an iterative solution to the DOA problem [2]. The application of Kalman filtering requires signal modeling by dynamic state equations and the assumption that the stochastic process involved is gaussian. Despite its generality, the KF has found limited application in sensor array processing, because it needs a precise modeling of the process to be estimated.

In a stochastic environment, the Kalman filtering is one of the best linear estimators. The KF can be readily used to estimate the states of a linear model with known parameters[4,5].If the model turns out be non-linear, a real time
Taylor approximation of the system function at the previous state and that of the observation function at the corresponding predicted position is considered which is the extended Kalman filter[4]. This EKF has already proved to be an effective tool for both state estimation and adaptive parameter identification [4,67].

The organization of the paper is as follows. In section 2 our approach in obtaining an AR model for the sensor array processing is explained. The EKF based algorithm for joint state and parameter estimation is explained in section 3. The simulation results are discussed in section in section 4 . Finally a summary of the results is made and conclusions are drawn in in section 5 .

\section{MODELING}

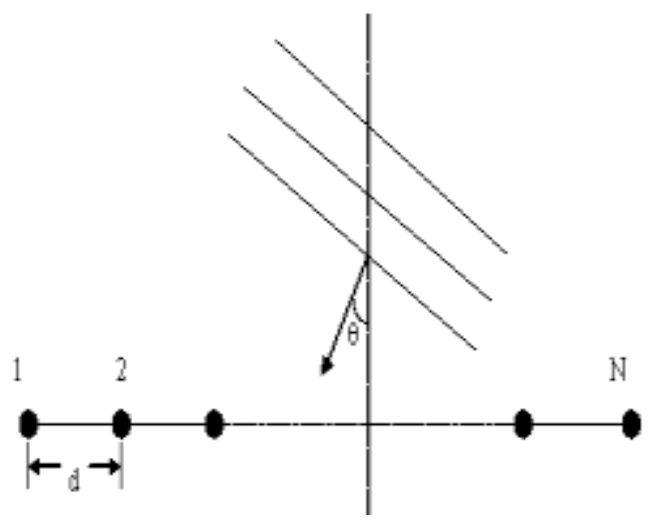

Fig. 1. Incident signal and sensor array

We have an incoming plane wave in a white noise background.The data vector $X(n)$ represents the data received by an array of $\mathrm{N}$ sensors and $\mathrm{M}$ is the total number of snapshots. The signal vector at a sensor can be decomposed in to

$\mathrm{X}_{\mathrm{n}}(\mathrm{k})=\mathrm{SX}_{\mathrm{n}}(\mathrm{k}-1)$ where $\mathrm{S}$ is a function of the parameter that enters non-linearly in to the model and $S=\left[\begin{array}{llll}a_{1} & a_{2} & \cdot & a_{m}\end{array}\right]$. The AR coefficients $a_{1}$ to $a_{m}$ are obtained from a finite set of measurements of the signals impinging on the first sensor and $\mathrm{X}_{\mathrm{n}}(\mathrm{k})=\sum_{\mathrm{j}=1}^{\mathrm{m}} \mathrm{a}_{\mathrm{j}} \mathrm{X}_{\mathrm{kj}}$ and $\mathrm{X}_{\mathrm{n}+1}(\mathrm{k})=\mathrm{X}_{1}(\mathrm{k}) \mathrm{e}^{\mathrm{j} 2 \pi \sin \theta \mathrm{d} / \lambda}$

, where $\mathrm{d}$ is the inter element spacing, $\lambda$ is the wave length of the signal and $\theta$ is the physical direction of arrival of the incoming plane wave.

Thus the system matrix can be formed as 
$\mathrm{A}_{\mathrm{K}}\left(\theta_{\mathrm{K}}\right)=\left[\begin{array}{ccccc}\mathrm{a}_{1} & \mathrm{a}_{2} & \cdot & \cdot & \mathrm{a}_{\mathrm{m}} \\ \mathrm{a}_{1} \varphi & \mathrm{a}_{2} \varphi & \cdot & \cdot & \mathrm{a}_{\mathrm{m}} \varphi \\ \cdot & \cdot & \cdot & \cdot & \cdot \\ \cdot \cdot \mathrm{a}_{1} \varphi^{\mathrm{N}-1} & \mathrm{a}_{2} \varphi^{\mathrm{N}-1} & \cdot & \cdot & \cdot \\ \cdot & \cdot & \mathrm{a}_{\mathrm{m}} \varphi^{\mathrm{N}-1}\end{array}\right]$

where $\varphi=\mathrm{e}^{\mathrm{j} 2 \pi \sin \theta \mathrm{d} / \lambda}$

The system can now be modeled as follows

$\left[\begin{array}{c}X_{1}(k) \\ X_{2}(k) \\ X_{3}(k) \\ X_{N}(k)\end{array}\right]=A_{k}\left(\theta_{k}\right)\left[\begin{array}{c}X 1(k-1) \\ X 1(k-2) \\ X 1(k-3) \\ X_{1}(k-N)\end{array}\right]$

\section{THE EXTENDED KALMAN FILTER SYSTEM IDENTIFICATION}

In this paper the EKF is applied to estimate the state vector, which contains DOA as its component. That is DOA is estimated in an adaptive manner. The unknown parameter DOA is not considered as deterministic. If $\theta_{\mathrm{k}+1}=\theta_{\mathrm{k}}=\theta$ the variance is zero and the EKF procedure only yields $\theta_{\mathrm{k}}=\theta_{\mathrm{k}-1}$ for all $\mathrm{k}$ independent of the observation data and this does not give any information on $\theta_{\mathrm{k}}$. By using variance in parameter $\theta_{\mathrm{k}}$ as zero, the unknown system parameter cannot be identified via EKF method.

The adaptive DOA estimation problem in the extended Kalman filter sense, is formulated in the following manner. Suppose the system state space description

$\mathrm{X}_{\mathrm{k}+1}=\mathrm{A}_{\mathrm{k}}\left(\theta_{\mathrm{k}}\right) \mathrm{X}_{\mathrm{k}}+\mathrm{W}_{\mathrm{k}} \xi_{\mathrm{k}}$

$\mathrm{Y}_{\mathrm{k}}=\mathrm{C}_{\mathrm{k}}\left(\theta_{\mathrm{k}}\right) \mathrm{X}_{\mathrm{k}}+\eta_{\mathrm{k}} \quad$ is considered where

$\mathrm{X}_{\mathrm{k}} \in \mathrm{R}^{\mathrm{n}}$ is the state vector, $\mathrm{Y}_{\mathrm{k}} \in \mathrm{R}^{\mathrm{r}}$ is the output vector, $\xi_{\mathrm{k}}$ and $\eta_{\mathrm{k}}$ are uncorrelated gaussian white noise sequence with zero mean and gaussian distribution having covariance matrices designated by $\mathbf{Q} \& \mathbf{R}$ respectively.

In this application the objective is to identify $\theta$ and hence it is considered as a random vector such as $\theta_{\mathrm{k}+1}=\theta_{\mathrm{k}}+\varepsilon$

$\varepsilon_{\mathrm{k}}$ is any zero mean gaussian white noise uncorrelated with $\eta_{\mathrm{k}}$ and with pre-assigned positive definite variances $\operatorname{Var}\left(\varepsilon_{\mathrm{k}}\right)=\mathrm{S}_{\mathrm{k}}$. Now the system (i) together with assumption (ii) can be reformulated as the non-linear model

$\left[\begin{array}{c}\mathrm{X}_{\mathrm{k}+1} \\ \theta_{\mathrm{K}+1}\end{array}\right]=\left[\begin{array}{c}\mathrm{A}_{\mathrm{k}}\left(\boldsymbol{\theta}_{\mathrm{k}}\right) \mathrm{X}_{\mathrm{k}} \\ \boldsymbol{\theta}_{\mathrm{k}}\end{array}\right]+\left[\begin{array}{c}\mathrm{W}_{\mathrm{k}}\left(\boldsymbol{\theta}_{\mathrm{k}}\right) \xi_{\mathrm{k}} \\ \boldsymbol{\varepsilon}_{\mathrm{k}}\end{array}\right]$

$\hat{\mathrm{Y}}_{\mathrm{k}}=\mathrm{C}_{\mathrm{k}} \theta_{\mathrm{k}} \quad 0\left[\begin{array}{c}\mathrm{X}_{\mathrm{k}} \\ 0\end{array}\right]+\eta_{\mathrm{k}}$

$\hat{\mathrm{Y}}_{\mathrm{k}}=\mathrm{X}(\mathrm{k})$, thus the measurement function $\mathrm{h}=1$. and the extended Kalman filter procedure is applied to estimate the state vector which includes $\theta_{\mathrm{k}}$ in an adaptive way.

\subsection{Algorithm for Adaptive Estimation of $\theta[8]$.} For $\mathrm{k}=1,2 \ldots$.

$$
\begin{aligned}
& {\left[\begin{array}{c}
\mathrm{X}_{\mathrm{k}, \mathrm{k}-1} \\
\theta_{\mathrm{k}, \mathrm{k}-1}
\end{array}\right]=\left[\begin{array}{c}
\mathrm{A}_{\mathrm{k}-1}\left(\theta_{\mathrm{k}-1}\right) \mathrm{X}_{\mathrm{k}-1} \\
\theta_{\mathrm{k}-1}
\end{array}\right]} \\
& \Lambda=\left[\begin{array}{cc}
\mathrm{A}_{\mathrm{k}-1}\left(\theta_{\mathrm{k}-1}\right) \mathrm{X}_{\mathrm{k}-1} & \frac{\partial}{\partial \theta}\left\{\mathrm{A}_{\mathrm{k}-1}\left(\theta_{\mathrm{k}-1} \mathrm{X}_{\mathrm{k}-1}\right\}\right. \\
0 & \mathrm{I}
\end{array}\right] \\
& \mathrm{P}_{\mathrm{k}, \mathrm{k}-1}=\Lambda \mathrm{P}_{\mathrm{k} \cdot \mathrm{k}-1} \Lambda^{\mathrm{T}}+\mathrm{M} \text { where } \\
& \mathrm{M}=\left[\begin{array}{cc}
\mathrm{W}_{\mathrm{k}-1}\left(\theta_{\mathrm{k}-1}\right) \mathrm{Q}_{\mathrm{k}-1}\left(\mathrm{~W}_{\mathrm{k}-1}\left(\mathrm{Q}_{\mathrm{k}-1)}\right)^{\mathrm{T}}\right. & 0 \\
0 & \mathrm{~S}_{\mathrm{k}-1}
\end{array}\right] \\
& \mathrm{G}_{\mathrm{k}}=\mathrm{P}_{\mathrm{k}, \mathrm{k}-1} \mathrm{C}_{\mathrm{k}}\left(\theta_{\mathrm{k}, \mathrm{k}-1}\right) \quad 0{ }_{-}^{\overline{\mathrm{T}}} \mathrm{S} \text { where } \\
& \mathrm{S}=\mathrm{C}_{\mathrm{k}}\left(\boldsymbol{\theta}_{\mathrm{k}, \mathrm{k}-1}\right) \quad 0 \underline{\mathrm{P}}_{\mathrm{k}, \mathrm{k}-1} \mathrm{C}_{\mathrm{k}}\left(\boldsymbol{\theta}_{\mathrm{k}, \mathrm{k}-1} \quad \overline{0}_{\underline{-}}^{-} \mathrm{R}_{\mathrm{k}}{ }_{-}^{-}\right. \\
& \mathrm{P}_{\mathrm{k}, \mathrm{k}}=\mathrm{I}-\mathrm{G}_{\mathrm{k}} \mathrm{Ck}(\theta \mathrm{k}, \mathrm{k}-1) \quad 0_{-}^{-} \quad \overline{\mathrm{P}}_{\mathrm{k}, \mathrm{k}-1} \\
& {\left[\begin{array}{c}
\mathrm{X}_{\mathrm{k}} \\
\theta_{\mathrm{k}}
\end{array}\right]=\left[\begin{array}{c}
\mathrm{X}_{\mathrm{k}, \mathrm{k}-} 1 \\
\theta_{\mathrm{k}, \mathrm{k}-1}
\end{array}\right]+\mathrm{G}_{\mathrm{k}} \mathrm{Y}_{\mathrm{k}}-\mathrm{C}_{\mathrm{k}}\left(\theta_{\mathrm{k}, \mathrm{k}-1}\right) \mathrm{X}_{\mathrm{k}, \mathrm{k}-1} \text {. }}
\end{aligned}
$$

\section{SIMULATION AND RESULTS}

Simulated data are used to evaluate the performance of the algorithm described in 2 and 3 respectively. A uniform linear array of 8 sensors as shown in figure 1 is used. To implement the EKF algorithm for parameter estimation, the state vector is augmented with the parameter $\theta$, which is the angle of arrival. Four sources with different DOAs $\left(-40^{\circ}, 22^{0}, 30^{\circ}\right.$ and $\left.60^{\circ}\right)$ were selected and white noise of different powers were added to the source signals to achieve suitable noise levels. Figures 2-5 demonstrates the convergence of the estimated DOAs with actual ones. Figures 6-9 show RMSEs and CRBs of the DOA estimates for the model discussed in section 2. Each point on the plot is obtained after hundred montecarlo simulations. The tuning of the process noise covariance $\mathbf{Q}$ and observation noise covariance $\mathbf{R}$ is done manually and are set to fixed values and do not form part of the estimation process in the EKF recursions. Although the use of fixed values may produce questionable convergence results, it has not created any problem in the results presented in this paper

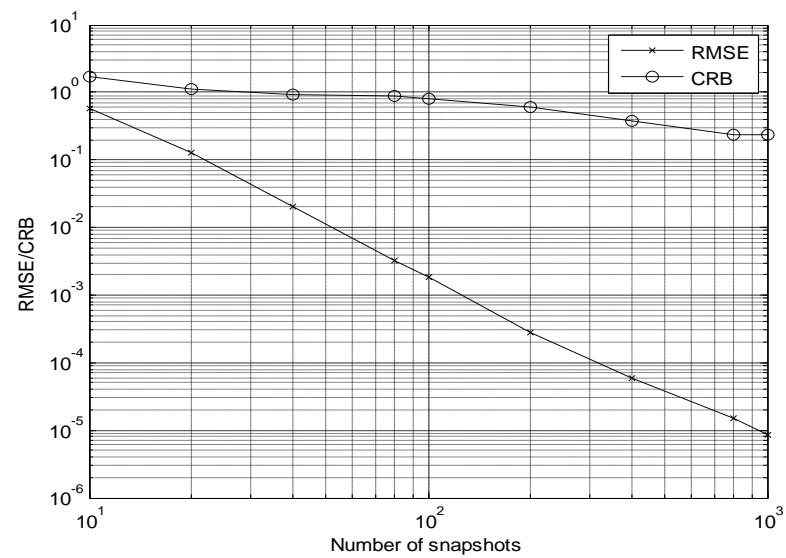

Fig.2 DOA estimation RMSEs and CRB verus number of snapshots for true $\mathrm{DOA}=-40 \mathrm{deg}$ 


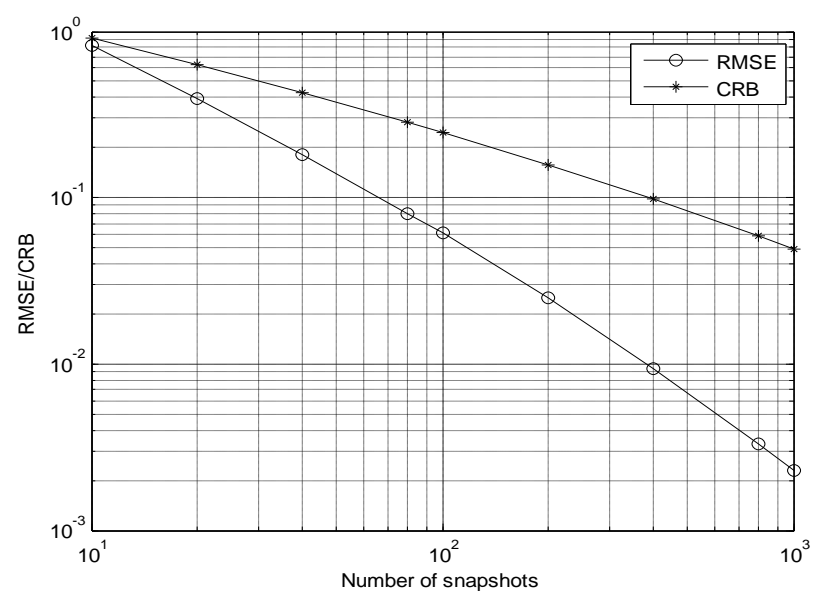

Fig.3 DOA estimation RMSEs and CRB versus number of snapshots for true $\mathrm{DOA}=22 \mathrm{deg}$

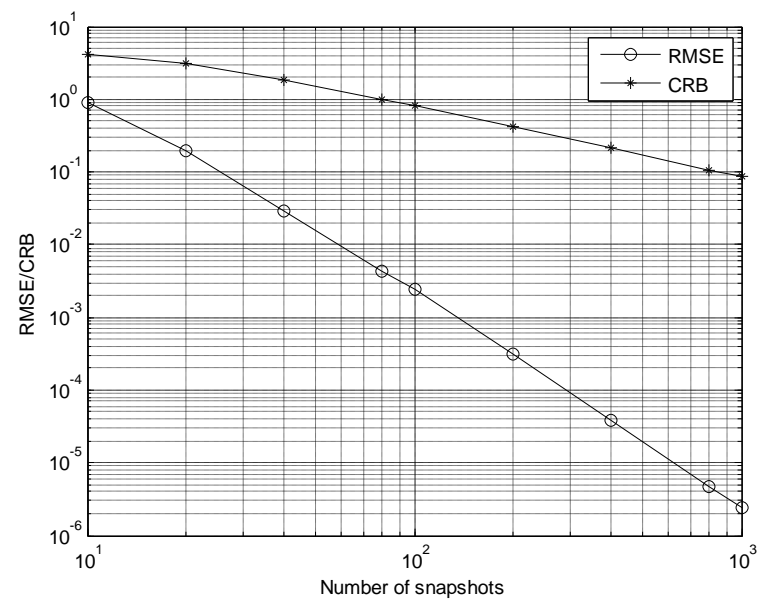

Fig.4 DOA estimation RMSEs and CRB versus number of snapshots for true $\mathrm{DOA}=30 \mathrm{deg}$

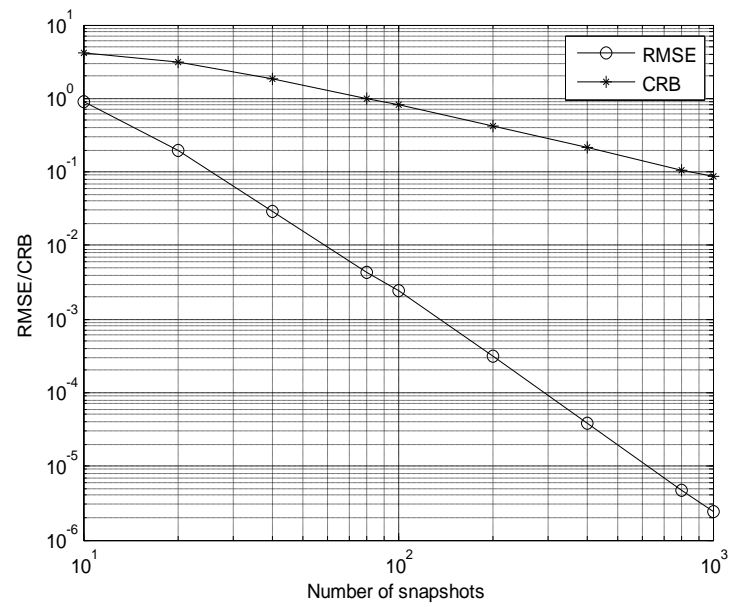

Fig.5 DOA estimation RMSEs and CRB versus number of snapshots for true $\mathrm{DOA}=60 \mathrm{deg}$

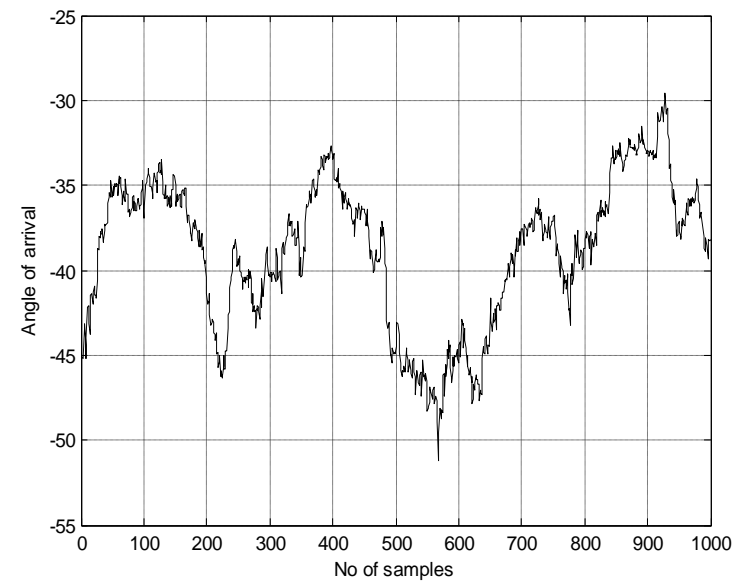

Fig.6 DOA estimate versus the number of samples for true $\mathrm{DOA}=-40 \mathrm{deg}$ at $\mathrm{SNR}=-5$

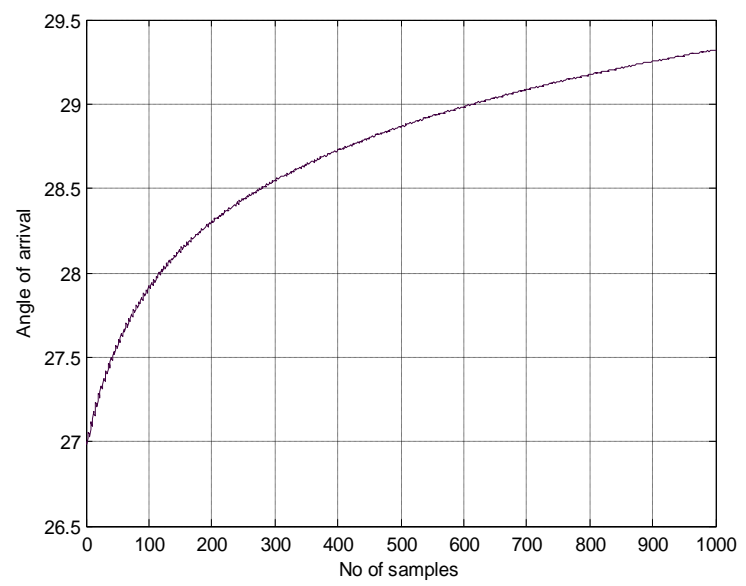

Fig.7 DOA estimate versus the number of samples for true $\mathrm{DOA}=30 \mathrm{deg}$ at $\mathrm{SNR}=0$

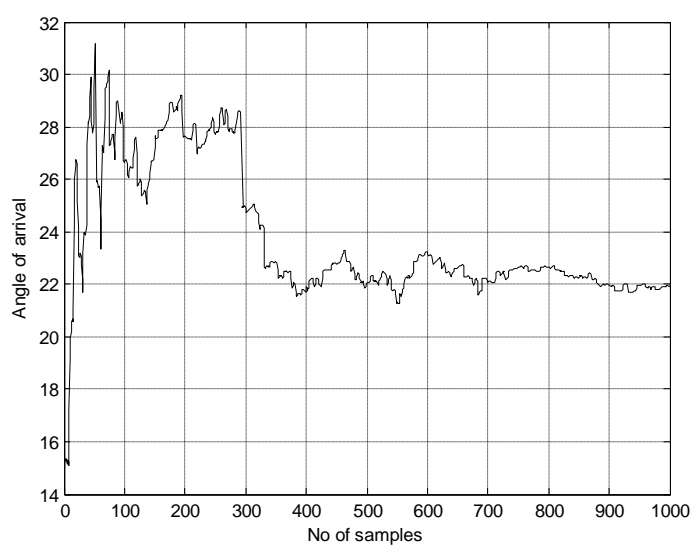

Fig.8 DOA estimate versus the number of samples for true $\mathrm{DOA}=22 \mathrm{deg}$ at $\mathrm{SNR}=3$ 


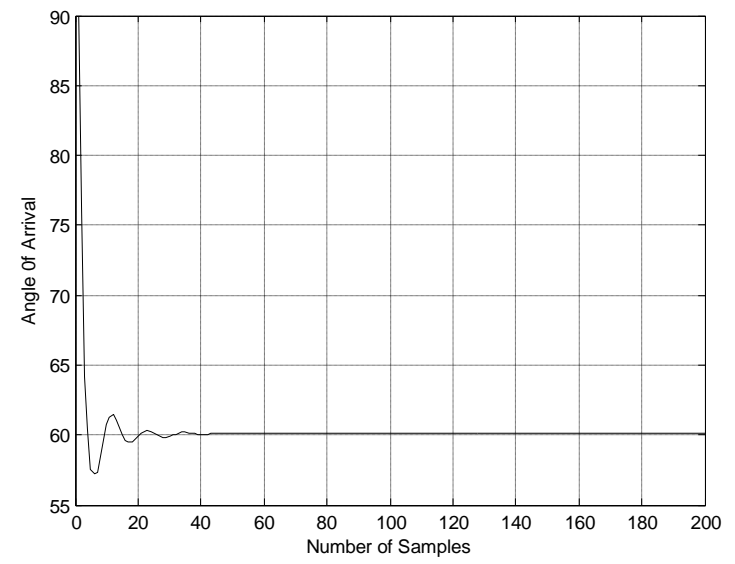

Fig.9 DOA estimate versus the number of samples for true $\mathrm{DOA}=60$ deg at $\mathrm{SNR}=5$

\section{CONCLUSION}

In this paper we have attempted to treat the DOA estimation as a system identification problem. The key to this algorithm is the use of AR for modeling and EKF for system identification. The DOA estimation is done in the presence of modeling error. The estimation is a two step procedure where, at first a parameterized state space realization of the array model is identified and then, the DOA parameter is extracted from the identified parameter. It is seen that the model along with the EKF algorithm gives better convergence to the true values, even at low SNRs. Further the
CRB and RMSE plots demonstrate that the results are promising. The estimation procedure adapted can be extended to broad band and arbitrary signals.

\section{REFERENCES}

[1] Pei Jung Chung, Johann F. Bohme, "Comparative convergence analysis of EM and SAGE algorithm in DOA estimation", IEEE Trans. Signal Processing, vol.49, 2001.

[2] Simon Haykin and Allan Steinhardt, 1992. Adaptive Radar Detection and Estimation. John Wiley \&Sons.

[3] Simon Haykin and Allan Steinhardt, 1992. Adaptive Radar Detection and Estimation. John Wiley \&Sons.

[4] Shen - Shu Xiong , Zhao - Ying, " Neural Filtering of coloured noise based on kalman filter structure", IEEE Trans. Instrumentation and Measurement, vol. 52, June 2003.

[5] A.H. Jaswinski, Stochastic Processes and Filtering Theory, 1970.Academic Press.

[6] Roberto Togneri,Li Deng, "Joint state and parameter estimation for a Target_directed non-linear dynamic system model”, IEEE Trans. Signal Processing, vol.51,.2003.

[7] K.Radhakrishnan, A. Unnikrishnan and K.G. Balakrishnan,2006. E.M based extended Kalman filter for estimation of rotor time-constant of induction motor, IEEE int. Symp. Industrial Electronics ISIE'06, Quebec, Canada.

[8] C.K. Chui and Chen, Kalman Filtering with Real- Time Applications. 1991. New York: Springer - Verlag, . 